研 究

\title{
マイクロ波照射下均一沈殿法による酸化銅粒子の生成
}

\author{
伊納 義孝的 1 , 小澤 正邦的 2 , 加藤 亮二的 2 , 籠橋 章的 1 \\ 的高砂工業株式会社, $=509-5401$ 土岐市䭾知町 2321. \\ 中2 名古屋工業大学セラミックス基盤工学研究センター， ５ 507-0071 多治見市旭ヶ 丘 10-6-29.
}

\section{Synthesis of CuO Powder by Homogeneous Precipitation Process under Microwave Irradiation}

\author{
Yoshitaka Ino ${ }^{\text {tr } 1}$, Masakuni Ozawa ${ }^{\text {tr } 2}$, Ryoji Katoh ${ }^{\text {tक } 2}$ and Akira Kagohashi ${ }^{\text {tr } 1}$ \\ ${ }^{2}$ Takasago Industry, 2321 Dachi-cho, Toki 509-5401, Japan. \\ मे $^{2}$ Ceramic Research Laboratory, Nagoya Institute of Technology, 10-6-29 Asahigaoka, Tajimi 507-0071, Japan.
}

Received June 7, 2010

\begin{abstract}
SYNOPSIS
We investigated the morphology of $\mathrm{CuO}$ powders synthesized by three processes: homogeneous precipitation, homogeneous precipitation under microwave irradiation, and heat treatment of precursor at $600^{\circ} \mathrm{C}$. Homogeneous precipitation process was applied to a mixed aqueous solution of copper precursor complex, which was obtained from cupper nitrate and hexamethylenetetramine. The $2.45 \mathrm{GHz}$ microwave irradiation to a precursor solution induced the formation of $\mathrm{CuO}$ powders with special morphology at $95^{\circ} \mathrm{C}$ in aqueous solution. Also the rapid formation of $\mathrm{CuO}$ from precursor by microwave was revealed in comparison with the processes without microwave irradiation.
\end{abstract}

KEY WORDS

microwave, cupper oxide, homogeneous precipitation, powder

\section{1 緒 言}

酸化銅 $(\mathrm{CuO})$ 微粒子の合成では, 薄膜, セラミック原料粉 や触媒原料などの用途によりさまざまな形態や粒度の材料が 必要となつている.工業的に安価な溶液法により繊維状, 棒 状, ナノ粒子などの形態制御の研究がなされている ${ }^{1-9)}$. Yang ら ${ }^{2)}$ は様々な形態の粒子が生成する可能性を指摘し, Zhang ら ${ }^{3)}$ やChen $5^{4)}$ は界面活性剂存在下水系でシャトル状粒子や花弁 状の形状の合成例を報告している．Leung ら”はへキサメチ レンテトラミンを用いた均一沈殿法で酸化銅を合成し,さら にLinag らやWang らはマイクロ波を照射した条件での酸化 銅ナノ粒子合成を報告している ${ }^{8.99}$. 本研究では, 酸化銅の形 態の特異性を引き出すことを放らって, 常圧での水系合成の ひとつとして有用な均一沈殿法において粒子生成へのマイク 口波照射する効果を調べる、マイクロ波照射すると特異な反 応促進効果や反応条件の低温化などの効果があるとされ，化 学反応に応用することによりさまざまな材料の創成の可能性 があると期待されている，また，他の加熱方法として，前駆 体粉末を電気炉により大気中で加熱することでこれらの粉末 の形状を比較し, マイクロ波加熱均一沈殿法の特徵を調べた.

\section{2 実験方法}

\section{1 試料の作製}

出発原料として硝酸銅三水和物 $(99.5 \%$ 米山薬品工業(侏)製, 以下硝酸銅とする), 沈殿剂としてへキサメチレンテトラミン ( $99 \%$ 和光純薬工業(㑣製, 以下HMTとする)を用いた. 蒸留水 $0.5 \mathrm{dm}^{3}$ に硝酸銅 $7.01 \mathrm{~g}(0.05 \mathrm{~mol} / \mathrm{l})$, HMT $72.3 \mathrm{~g}(0.3 \mathrm{~mol} / \mathrm{l})$ として，両者のモル比 $1: 6$ の割合で HMT 及び硝酸銅をそれ ぞれ別に入れスターラーで30分摫挥した. 硝酸銅水溶液を攪 抖しながら HMT 溶液をこれに加えてさらに 1 時間攪拌した。 沈殿物をろ過し $60^{\circ} \mathrm{C}$ で 24 時間乾燥させ前駆体を得た。原料 金属とHMTの混合比ついては,これまでの著者らの検討例 を参考にした ${ }^{10)}$.

次に, 以下の異なる方法により酸化銅を合成した.上記の 乾燥した前駆体を電気炉内大気中, $600^{\circ} \mathrm{C}$ で 1 時間加熱し粉 末試料を得た。均一沈殿法では, 前駆体を含む水溶液を還流 器付き丸底フラスコ内に入れマントルヒータを用いて約 $5^{\circ} \mathrm{C} /$ 分で昇温し $95^{\circ} \mathrm{C}$ に達した後 3 時間保持し沈殿を得た.この沈

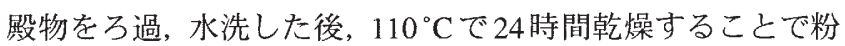
末試料を得た、マイクロ波照射均一沈殿法による合成実験は 
以下のように行った. 前駆体を含む水溶液を四国計測社製マ イクロ波合成装置に置いた還流器付きの丸底フラスコに入れ， $2.45 \mathrm{GHz}$ のマイクロ波を照射した。照射により温度上昇があ るのでその温度を入力電力制御方式により $95^{\circ} \mathrm{C} に$ 保持した. 温度保持中におけるマイクロ波は, 連続照射状態(ON/OFF制 御でなく)で入力がフィードバックされている．保持時平均

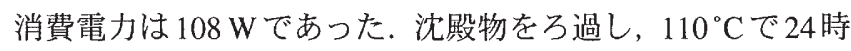
間乾燥させ, 粉末試料を得た。

\section{2 試料の評価}

生成物の結晶相の同定を粉末 X 線回折装置 (XRD, Rigaku Rint2000) で行った. 測定には管電圧 $40 \mathrm{kV}$ ，管電流 $40 \mathrm{~mA}$ の 条件で発生した $\mathrm{CuK} \alpha$ 線を用いた. 生成粒子の形態は走查型 電子顕微鏡 (SEM, JEOL JSM-7000F) を用いて観察した. 生成 粒子の平均粒径はSEM 写真によるものである.

\section{3 結果と考察}

\section{1 前駆体の生成}

硝酸銅溶液から HMT 添加による沈殿生成がみられたので この反応前駆体を単離した. そのXRD図形をFig.1に示す. 生 成した錯体の XRD 図形は JCPDS データから $\mathrm{Cu}_{4}\left(\mathrm{NO}_{3}\right)_{2}(\mathrm{OH})_{6}$ 相(JCPDS74-1749) と判断される. この錯体の SEM 像を Fig.2 に示す. 結晶は板状でその微細な粒子が相互に絡み合った状

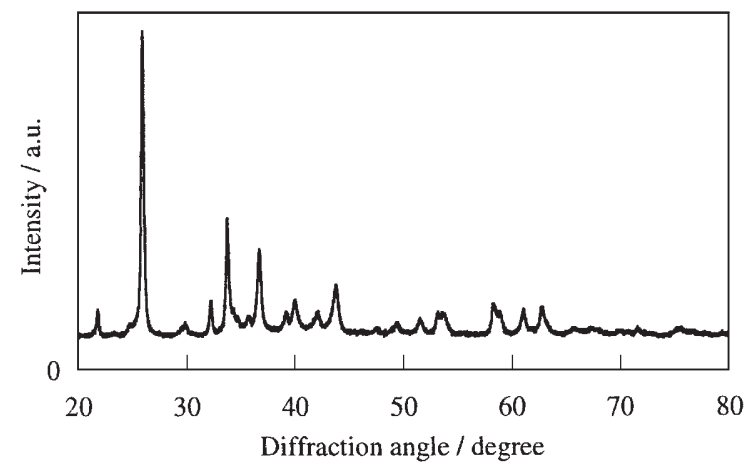

Fig.1 XRD pattern of the $\mathrm{Cu}$ complex precursor.

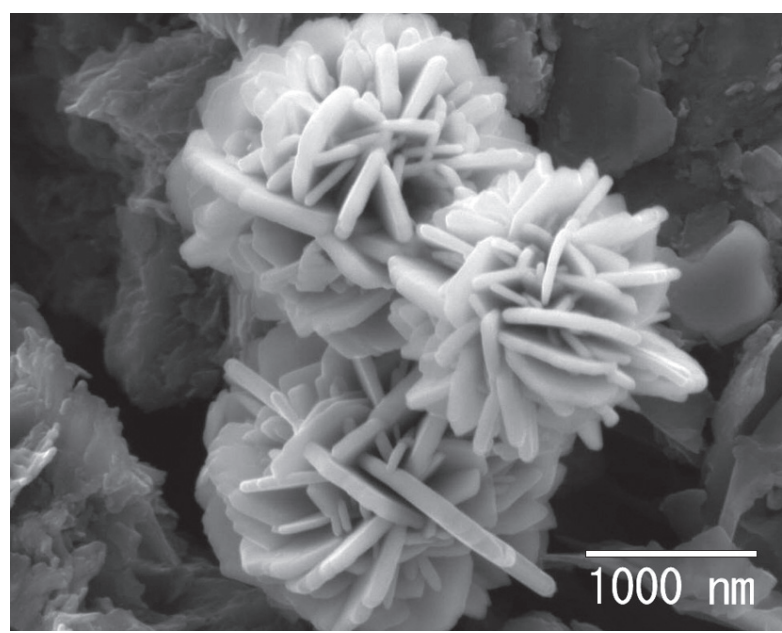

Fig.2 SEM image of a precursor powder.
態で沈殿となり, 微結晶集合体の粒子となっていた. 粒子内 での板状結晶は㕌さ50 100 nmの譬の絡み合った状態で存在 し, 粒子全体は平均粒径約 $2 \mu \mathrm{m}$ の粒子であった. 沈殿は緑色 を呈する粒子として水溶液中に分散して比較的安定なコロイ ド溶液状態で存在した.

\section{2 熱処理により生成した酸化銅}

上記の錯体を乾燥後, 電気炉で $600^{\circ} \mathrm{C}$ に加熱して得られた 試料の SEM 像を Fig.3に示す. 球状で粒径が $100 \sim 200 \mathrm{~nm}$ の 粒子が集合した約 $2 \mu \mathrm{m}$ の粉体に変化した。XRD 図形におい ては $\mathrm{CuO}$ 相であり錯体の分解のため生じた $\mathrm{CuO}$ 微粒子が疑 集体となったものと考えられる.

3.3 均一沈殿法により生成した酸化銅

Fig.4 (a)にマントルヒータ加熱下均一沈殿法で合成した粉 末のXRD図形を示す. 単相のCuOであるが, Fig.4(b)に示し た電気炉加熱 $600{ }^{\circ} \mathrm{C}$ で得られた試料よりもピークはブロード で結晶性が低かった. Fig.5にマントルヒータ加熱下均一沈殿 法で生成した酸化銅のSEM像を示す. $1 \sim 3 \mu \mathrm{m}$ の粒径で木の 葉状の粒子が生成した. 個々の粒子はいずれもやや平たい紡 鍾形状を示しているのが特徴である.この形態は, Zhang ら³ が報告した界面活性剂存在下で水系合成で生成したシャトル

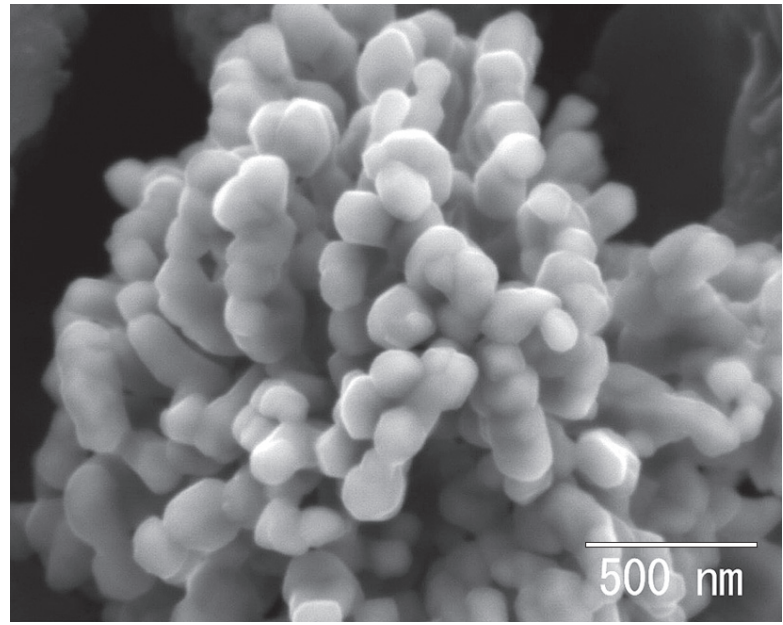

Fig.3 SEM image of CuO powder by heat-treatment of precursor at $600^{\circ} \mathrm{C}$ for $1 \mathrm{~h}$ in air.

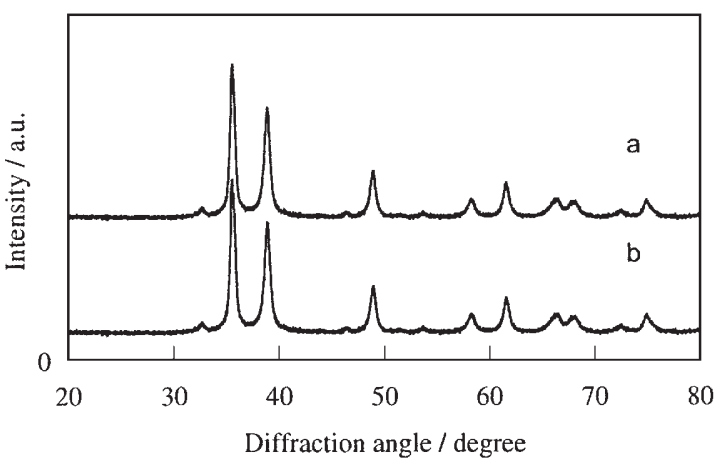

Fig.4 XRD patterns of CuO powders (a) by homogeneous precipitation, and (b) by the heat-treatment of precursor at $600^{\circ} \mathrm{C}$ for $1 \mathrm{~h}$ in air. 


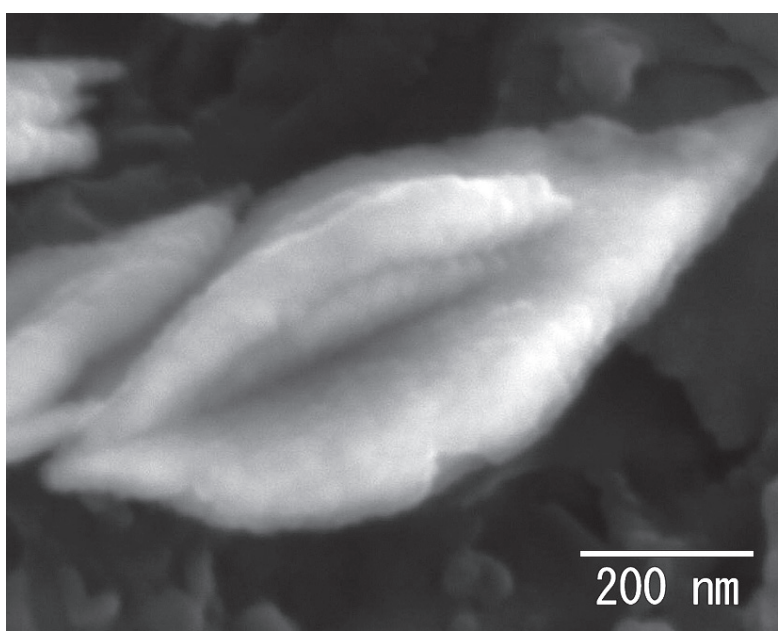

Fig.5 SEM image of $\mathrm{CuO}$ powder by homogeneous precipitation.

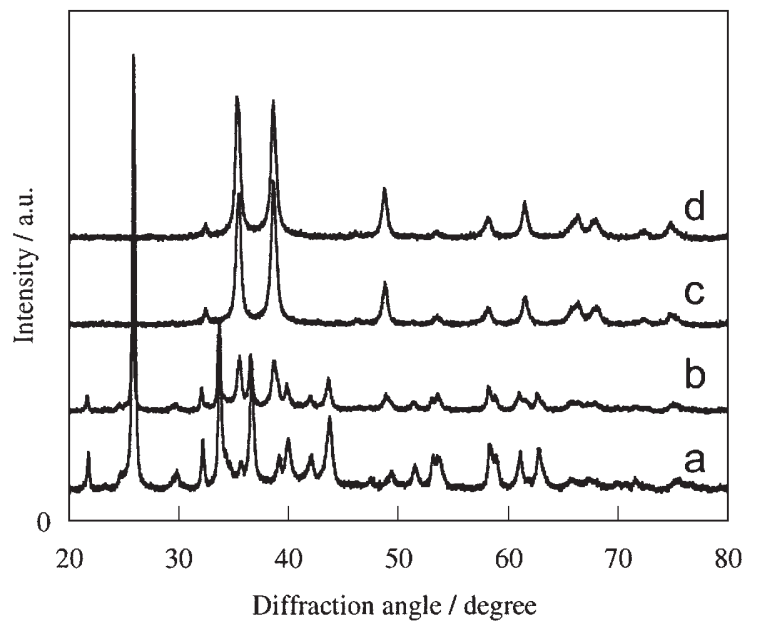

Fig.6 Change of XRD patterns for precipitation heated at $95^{\circ} \mathrm{C}$ for (a) 0 (Cu complex precursor), (b) 10, (c) 30, (d) 60 minutes under microwave irradiation.

状形態や, $\mathrm{Chen}^{4)}$ らによる共沈法での粒子の形状とよく似て いる.しかし本研究での方が粒子は大きく厚い形状であった. 本実験での酸化銅粒子の生成は, 温度上昇にともなう前駆体 の分解で溶液中に拡散した銅イオンが, HMTの分解にともな うアルカリ条件への $\mathrm{pH}$ 変化によって引き起こされる. $95^{\circ} \mathrm{C}$ でおこる沈殿生成反応であり, 通常の均一沈殿法による生成 過程が推定される.

3.4 マイクロ波照射均一沈殿法により生成した酸化銅

Fig. 6 に, $95^{\circ} \mathrm{C}$ で $10 \sim 60$ 分の各時間保持して合成した試料 と前駆体のXRD 図形を比較して示す． $95^{\circ} \mathrm{C}, 10$ 分保持です

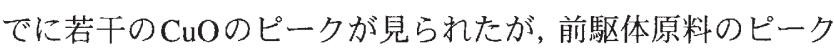
も残っていることが確認される。Fig.7 保持時間の関係を示す. 30 分以上での保持では完全に $\mathrm{CuO}$ の ピークのみが観測され短時間で完全な $\mathrm{CuO}$ 相に転換すること がわかる. マントルヒータでは昇温に40分程度要するので加 熱される時間は長いのに対し, マイクロ波加熱では5分以内

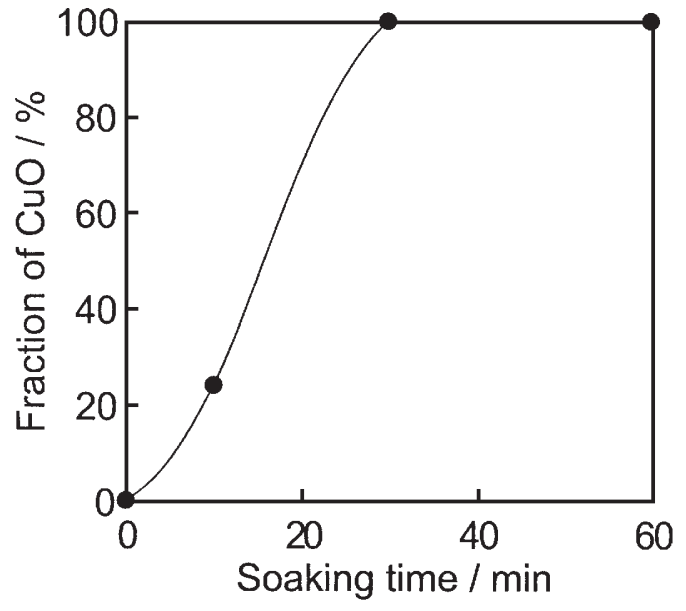

Fig.7 Fraction of $\mathrm{CuO}$ powders by homogeneous precipitation under microwave irradiation.

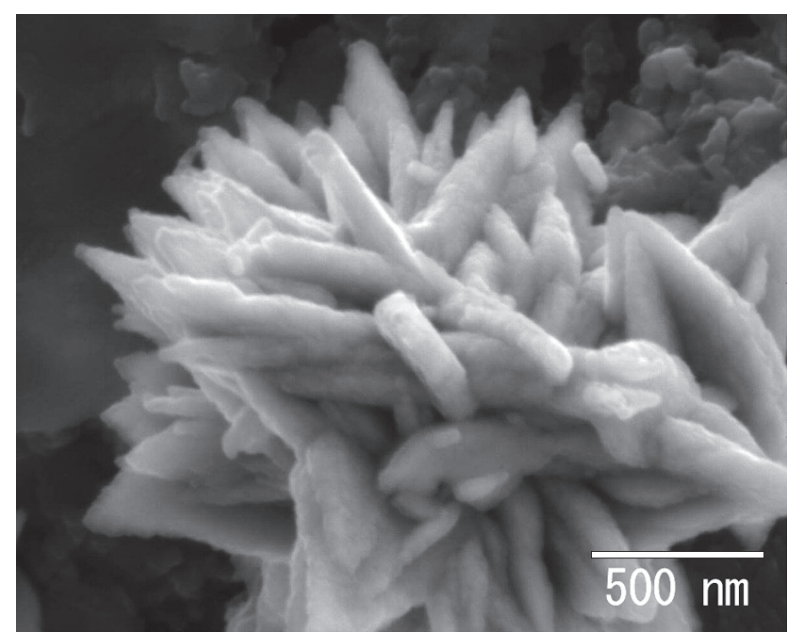

Fig. 8 SEM image of $\mathrm{CuO}$ powder by homogeneous precipitation under microwave irradiation.

に $95^{\circ} \mathrm{C}$ 達するという昇温の敏速性には違いがあり反応に必 要な時間短縮が可能になっている. Fig.8にマイクロ波加熱 60 分保持で合成された $\mathrm{CuO}$ 試料のSEM写真を示す. 径(幅) 約 $100 \mathrm{~nm}$ で長さ $200 \mathrm{~nm} \sim 1 \mu \mathrm{m}$ のトゲ棒状の突起を複数もち, 全 体の粒径が $1 \sim 2 \mu \mathrm{m}$ の粒子が確認された. 前駆体の板状微結 晶に相当する大きさでとげ状微結晶が生成しその集合体と なっており, 凝集粒子全体の大きさは前駆体よりいくらか小 さい.上述のマントルヒータにより合成された試料は木の葉状 であるのと違い特異な形状を示した.この形状は, Liang ら ${ }^{8)}$ やWang ら"が報告しているマイクロ波照射下合成の粒子と も異なっており本研究ではじめて見られた形状である.

このようなマイクロ波照射により生成する粒子形状が異な る機構については, 銅錯体塩が溶解あるいは分散している溶 液にマイクロ波を照射するとき少なくとも反応場で錯体分子 がマイクロ波を吸収して反応が励起される過程が重要と考え られる、錯体が直接エネルギ一を吸収する場合では，外部か ら熱伝導によって比較的均一に温度がかけられている場合と 
異なるため, 結晶の核生成が錯体の分解した部分から速やか に起こり，またその成長においての物質移動が近傍でおこる のでその生成速度が速くなる可能性がある. 硝酸銅水溶液と HMT水溶液の混合物では, まず前駆体錯体が生成するがこれ を加熱すると前駆体が分解すると同時に沈殿剂が分解し $\mathrm{pH}$ が上昇することで溶液中の反応で $\mathrm{CuO}$ の生成条件に達する. この化学反応自体は, マイクロ波照射下でも同じであると考 えられるが, マイクロ波の場合は錯体の微結晶の形態を維持 したまま, マイクロ波加熱による局所反応場が生じているこ とが考えられる．その際，部分的に溶解した銅イオンと水酸 物イオンの反応が, 元の錯体粒子の形状が崩される前にその 近傍で起こるとすると，錯体の凝集性を維持した酸化銅が生 成する可能性がある。一方, マントルヒー夕加熱均一沈殿過 程では, 錯体の溶解が起こった後, 別の場所で核生成と成長 が比較的ゆっくり起こるため, 元の形娟を残すことなく木葉 状粒子へ成長すると考えられる. 形態制御におけるマイクロ 波照射効果とその機構の詳細の解明については今後の課題で ある。

\section{4 総 括}

硝酸銅水溶液と HMT 水溶液の混合物にマイクロ波照射に よる加熱ならびにマントルヒー夕による外部加熱によって低 温で酸化銅粒子の合成研究を行った. マイクロ波照射による 加熱では, 原料水溶液を加熱することにより複数のトゲ状の 突起を持った酸化銅が合成された. マントルヒータによる外 部加熱では木の葉状の酸化銅粒子が得られた. 一方, 前駆体 粉末を電気炉により加熱することにより球状の粒子が集合し た粉末が得られ，同じ出発原料から加熱方法を変えることで 様々な形状制御が可能になることがわかった．とくにマイク 口波を用いた均一沈殿法での合成においては $100^{\circ} \mathrm{C}$ 以下の水 溶液で特異形状粒子が30分以内で敏速に生成することを見出 した.

\section{謝辞}

本研究の内容は, 平成 21 年度粉体粉末冶金協会秋季大会一
般セッションにて発表された. 研究の一部は文部科学省都市 エリア産学官連携促進事業「環境調和型セラミックス新産業 の創出」の支援により実施した.

\section{文献}

1) R. Rodriguez-Clemente, R. Serna, M. Ocana, and E. Matijevic: "The relationship of particle morphology and structure of basic copper (II) compounds obtained by homogeneous precipitation", J. Cryst. Growth, 143(1994)277-286.

2) R. Yang and L. Gao: "Novel Way to Synthesize CuO Nanocrystals with Various Morphologies", Chem. Lett., 33(2004)1194-1195.

3) Y. Zhang, S. Wang, X. Li, L. Chen, Y. Qian, and Z. Zhang: "CuO shuttle-like nanocrystals synthesized by oriented attachment", J. Cryst. Growth, 291(2006)196-201.

4) D. Chen, G. Shen, K. Tang, and Y. Qian: "Large-scale synthesis of $\mathrm{CuO}$ shuttle-like crystals via a convenient hydrothermal decomposition route", J. Cryst. Growth, 254(2003)225-228.

5) Z. Hong, Y. Cao, and J. Deng: "A convenient alcohothermal approach for low temperature synthesis of $\mathrm{CuO}$ nanoparticles", Mater. Lett., 52(2002)34-38.

6) J. Zhu, D. Li, H. Chen, X. Yang, L. Lu, and X. Wang: "Highly dispersed $\mathrm{CuO}$ nanoparticles prepared by a novel quickprecipitation method", Mater. Lett., 58(2004)3324-3327.

7) D. Leung, A. Djurisic, Z. Liu, M. Xie, J. Gao, and W. Chan: "CuO nanostructures prepared by a chemical method", J. Cryst. Growth, 282(2005) 105-111.

8) Z. Linag and Y. Zhu: "Microwave-assisted Synthesis of Singlecrystalline CuO Nanoleaves", Chem. Lett., 33(2004) 1314-1315.

9) H. Wang, J. Xu, J. Zhu, and H. Chen: "Preparation of $\mathrm{CuO}$ nanoparticles by microwave irradiation", J. Cryst. Growth, 244 (2002)88-94.

10) M. Ozawa, R. Onoe, and H. Kato, "Formation and decomposition of some rare earth $(\mathrm{RE}=\mathrm{La}, \mathrm{Ce}, \mathrm{Pr})$ hydroxides and oxides by homogeneous precipitation", J. Alloy. Compods., 408(2006) 408-412. 